\title{
Nanomaterials for sensing applications
}

\begin{abstract}
This review article is focus on the role of nanomaterials in gas sensing applications. Different kinds of nanomaterials have been widely used to detect toxic and pollutant gases. The gas sensing mechanism of nanomaterials is related to surface reaction, which is highly influenced by several factors like surface capping/ structure directing agents, modifying morphology, catalysis, working temperature.
\end{abstract}

Keywords: Nanomaterials, Nanostructure, Sol-gel, pH, Temperature, Stable oxygen anions, Ammonia gas, Hydrogen, Ethanol, Methane, Formaldehyde, Carbon monoxide, Poly pyrrole, Titanium dioxide, Tin oxide, Zinc Oxide, Benzene, Toluene, Xylene, Alcohol
Volume 3 Issue 5 - 2016

\section{Pratima Chauhan, Shiva Sharma \\ Department of Physics, University of Allahabad, India}

Correspondence: Pratima Chauhan, Department of Physics, University of Allahabad, Allahabad, Uttar Pradesh, Po. Box: 211002,India Email shivasharmaau@gmail.com

Received: April 09, 2016 | Published: May 12, 2016
Abbreviations:LPG, Liquefied Petroleum Gas; CNTs, Carbon Nano Tubes; SWNTs, Single Walled Carbon Nanotubes; PANI, Poly Aniline; FTO, Fluorine Doped Tin Oxide; PVA, Poly Vinyl Alcohol; CTABr, Cetyl Trimethyl Ammonium Bromide; VOCs, Volatile Organic Compounds

\section{Introduction}

The nanoworld has been played a great role in the scientific and technological development in universe. The discovery of nanomaterials such as carbon fullerenes in 1985, carbon nanotubes in 1991 and ordered mesoporous materials in 1992 makes a revolution in the field of nanotechnology.$^{1-4}$ Nanomaterials can be differentiated into various categories on the bases of their dimensionality such as one dimensional (nanowire, nanotube), two dimensional (nanosheets), and three dimensional (nanoparticles) etc.

Nanomaterials are one of the most studied materials because at this level unique optical, magnetic, electrical and mechanical properties emerge. These emergent properties have attracted the attention of users in various applications such as catalyst, gas sensors, batteries, optoelectronic devices, biomedical and agricultural applications .5-9 Among them, specific type of nanomaterials like pure and mixed oxides, organic based material are receiving a growing attention for gas sensing applications during last few years because they can enhance the sensitivity, selectivity and the response time remarkably. The nanomaterials of wide band gap have been proven to be excellent gas sensing materials with high response. The advantage of nanomaterials based gas sensors over bulk can be understood as nanosize grains are almost depleted of carriers (most carriers are trapped in surface state) and exhibit poor conductivity than bulk in ambient conditions. Hence when these are exposed to gas, exhibit greater conductance changes as more carriers are activated from their trapped states to the conduction band than with bulk sized grain. It is known that the morphologies, particle sizes and dimensionality of nanomaterials play a key role in observing their sensing characteristics.${ }^{10}$ Among these the crystallite size has an impact on the gas sensitivity i.e. maximum sensitivity is achieved only if the crystallite size within the film is comparable with its space charge layer thickness.$^{11-13}$

The nanomaterials with different morphology like size confinement in two coordinates also offers better sensitivity to surface chemical reaction due to large surface to volume ratio and small diameter comparable with Debye length.$^{14-17}$ There are many methods for achieving the above. Generally pure nanomaterials divided into two parts namely n-type and p-type nanomaterials. Up to now several nanomaterials have been successfully used as sensing materials for detecting reducing and oxidising gases by conversion of information in terms of electrical signals when exposed to corresponding test gas.$^{18-24}$ Nanomaterials can be synthesised by following two different approaches like bottom up approach (chemical method, electrochemical method, sol-gel, Solvothermal etc.), in which material is build up from bottom i.e. atom by atom and top down (ball milling, laser ablation, lithography) in which material is synthesized from initially bulk materials.$^{25-32}$ According to literature survey many researchers have shown that the various kind of nanomaterials including different dopant, catalysis, adhesive, binders, surfactant all have been used to enhance the sensing characteristics of sensors made from these materials. In addition to the above, their film fabrication method also provides another variable for sensor design.$^{33-52}$ As a simple review of nanomaterials for sensing applications, this article will focus on the principle, film deposition method and use of a range of nanomaterials for gas sensors. This article will also focus on the various factors that have direct impact on sensitivity, selectivity, and response time of nanomaterials.

\section{Synthesis of nanomaterials}

Generally Nanomaterials have synthesized by approaching two different method bottom up and top down. Both the methods have received great attention because of their unique advantages like prepared nanostructures with less defects, more homogeneous chemical composition, and different range of ordering. Bottom up approach provides synthesis of material from atom by atom, molecule by molecule while top down provides preparation of nanomaterials from bulk materials (Figure 1).

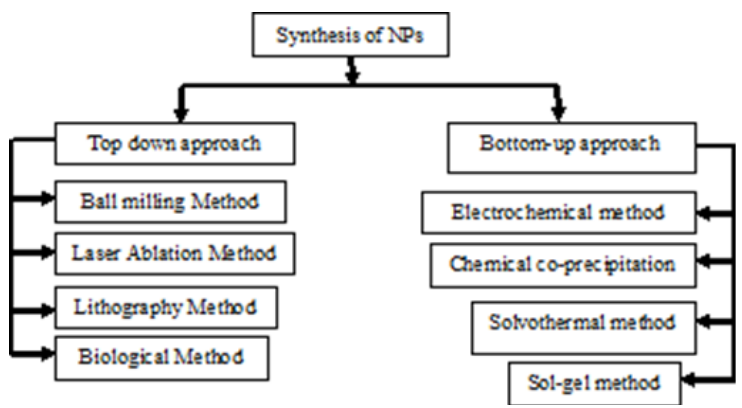

Figure I Schematic representation of synthesis of nanoparticles.

Mostly bottom up approach is preferred for synthesizing nanoparticles instead of top down. It provides uniform nanoparticles with controlled particle size with low cost and simplicity. There are several factors which also affects the synthesis of nanoparticles like precursor, solvent (water, polar/non-polar organic solvents), reducing agents (depends on the nature of precursors), capping agents/ 
stabilizing agents, heat treatment, pressure effect, and $\mathrm{pH}$ value of solution.

\section{Working principle of gas sensors}

Generally nanomaterials for gas sensing applications are characterised into two types of categories like n-type nanomaterials and p-type nanomaterials. The n-type nanomaterials have electrons as majority charge carriers while p-type nanomaterials have holes as a majority charge carriers. A range of nanomaterials from group III-VI called transition metal and their oxides with $\mathrm{d}^{0}-\mathrm{d}^{10}$ electronic configurations are found to have lots of characteristics for sensing applications. The sensing behaviour of nanomaterials is based on electrochemical changes, catalytic combustion or resistance modulation of these materials. Metal oxide sensors are used based on the principle of gas adsorption on the surface that leads to a change in the electrical resistance or conductivity of these nanomaterials. The gas sensing mechanism of metal oxide nanomaterials gas sensors is complex and basically depends upon the adsorption/ desorption of test gases on their surfaces ..$^{53-54}$

\section{Sensing mechanism}

The gas sensing mechanism of nanomaterials for gas detection is quite complex to explain and is based on the resistance change due to the chemical and electronic interaction between the test gas and the nanoparticles. This complexity occurs due to the various influencing parameters like chemical composition, temperature, humidity and modified surface morphology. The sensing mechanism includes the adsorption ability, surface properties and catalytic effect. For sensor devices made up of $n$ - type nanomaterials, when come into air environment, the oxygen will interact with such nanomaterials and capture the electrons from the conduction band of it to generate anionic species on the surface of sensor materials.$^{55-57}$ This will result in an electron depletion layer which enlarges electron transport barrier between nanoparticles. Thus, the anionic species adsorbed on the surface of nanomaterials sensor influences the resistance or conductance of nanomaterials based devices. During adsorption of Oxygen on the surface of nanomaterials, three types of stable oxygen anions namely $\mathrm{O}^{2-}, \mathrm{O}^{-}, \mathrm{O}^{2-}$ generates.$^{58-60} \mathrm{The}$ whole reaction is given in steps as below:

$$
\begin{gathered}
\mathrm{O}_{2} \text { (gas) } \leftrightarrow \mathrm{O}_{2} \text { (adsorbed) } \\
O_{2} \text { (adsorbed) }+e^{-} \leftrightarrow O_{2}^{-}(\text {ads }) \\
O_{2}^{-} \text {(ads) }+e^{-} \leftrightarrow 2 O^{-}(\text {ads }) \\
O^{-} \text {(ads) }+e \leftrightarrow O^{2-}(\text { ads })
\end{gathered}
$$

In the presence of test gas, the gas molecules will react with the adsorbed anionic species at the surface of nanomaterials and release the trapped electrons back to nanomaterials conduction band which leads to a reduced electron depletion barrier and contracted electron transport barrier ${ }^{61-64}$ The reverse is true for p-type nanomaterials.

\section{Experimental set-up and fabrication of sensor devices}

For gas sensing measurement, as synthesized nanomaterials are mixed with suitable organic solvent and deposited on a conducting substrate like Indium Tin Oxide coated glass plate, Alumina substrate with conducting electrodes and printed circuit board in the form of thin or thick film as shown below in Figure 2.
Such type of films are made via using spin coating method, screen printing method and electron beam deposition method. After being ready, the sensor device (thin or thick film) is placed in the test chamber of the measuring system and measure the resistivity or conductivity of the sensor device in the absence and presence of the test gas as shown in Figure 3.

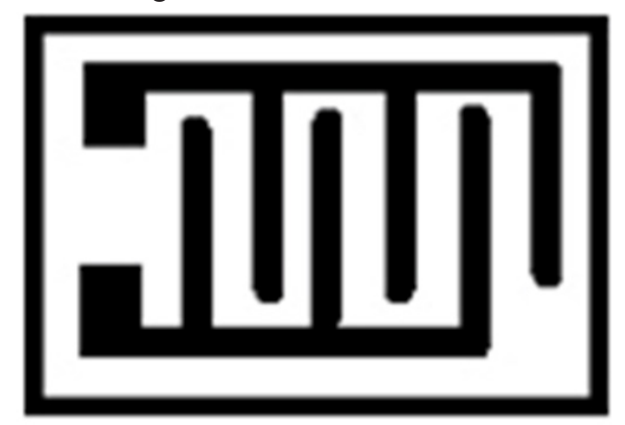

Figure 2 Glass substrate with inter digitated electrodes for making gas sensor.

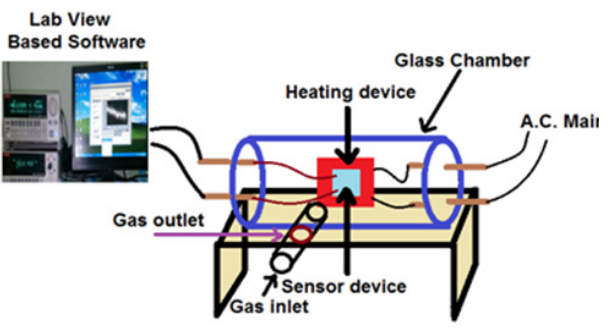

Figure 3 Schematic representation of gas sensing setup.

The measuring system consists of a gas sensing chamber, test gas or their mixtures, power supply, heater and the keithley source measure unit. The gas sensing chamber has two valve inlet and outlet valves. The inlet valve is connected to gas and the outlet valve is connected to an air pump to exit the test gas away.

\section{Applications in gas sensing devices}

During last few decades, the use of several kinds of gases in different areas like domestic, industries, food packaging, laboratories are creating a severe scene for us due to excess of these. So it is necessary to develop a device which is useful in detection of toxic and harmful gases. Many efforts have been done for developing such devices. But nanomaterials are playing a great role in developing these devices due to its potential applications. The sensing mechanism is based on changes in electrical resistance or conductance of nanomaterials due to chemical interaction in between the gaseous species and the nanomaterials. The charge transfer process induced by chemical interactions determines the resistance of the nanomaterials. If the nanomaterials are n-type the resistance decreases in presence of reducing gases such as Methane, Liquefied Petroleum gas (LPG), Ammonia gas $\left(\mathrm{NH}_{3}\right)$ while that of increases for p-type nanomaterials.

Different nanomaterials with various morphologies produced by using various synthesis processes were tested for reducing gases ${ }^{65}$ Zinc Oxide nanorods produced by hydrothermal method were tested as LPG sensors ${ }^{65}$ It was found that $\mathrm{ZnO}$ nanorods provide a good response to LPG and enhancing the response of those using zinc stannate micro cubes. The sensor response was found to be temperature dependent and exhibited maximum at $250^{\circ} \mathrm{C}$

The role of $\mathrm{ZnO}$ nanomaterials and their nanocomposites have been investigated for gas sensing application. Different $\mathrm{ZnO}$ nanostructures like nanowires, nanobelts and tetrapod have been prepared and used for analysing sensitivity to $\mathrm{H}_{2} \mathrm{~S}$ and $\mathrm{NO}$ gases. The effect of 
different nanostructures on response of n-type semiconductor $\mathrm{ZnO}$ to both shows that the response to $\mathrm{H}_{2} \mathrm{~S}$ arises due to changes in grain boundary resistance while the response to $\mathrm{NO}$ arises due to changes in both intragrain and grain boundary resistances. The response of these structures to $4 \mathrm{ppm}$ of $\mathrm{H}_{2} \mathrm{~S}$ shows that tetrapod have maximum while polycrystalline material has minimum sensitivity to $\mathrm{H}_{2} \mathrm{~S}$. The films made up of tetrapod were found to be sensitive to $1 \mathrm{ppm}$ due to oxygen vacancies and defects in lattice which create adsorption sites for oxygen.$^{54}$ Several literatures reported that the use of catalyst or promoters because of good dispersion to the nanomaterials is the most effective way to enhance the sensitivity of nanomaterials ${ }^{66-67}$ Ag NP embedded $\mathrm{ZnO}$ nanorods developed by photochemical method were investigated for ethanol sensing ${ }^{66} \mathrm{Ag}-\mathrm{ZnO}$ nanorods exhibited enhance response to ethanol at $10 \mathrm{ppm}$ than pure- $\mathrm{ZnO}$ nanorods. The $\mathrm{Ag}-\mathrm{ZnO}$ nanorods were also found to be highly selective for ethanol in between the mixture of Ethanol $\left(\mathrm{C}_{2} \mathrm{H}_{5} \mathrm{OH}\right)$, hydrogen $\left(\mathrm{H}_{2}\right)$, methane $\left(\mathrm{CH}_{4}\right)$, ammonia $\left(\mathrm{NH}_{3}\right)$, methanol $\left(\mathrm{CH}_{3} \mathrm{OH}\right)$, formaldehyde $(\mathrm{HCHO})$, carbon monoxide $(\mathrm{CO})$ and acetone $\left(\mathrm{CH}_{3} \mathrm{COCH}_{3}\right)$ (the concentration of all these gases was $50 \mathrm{ppm})$.

One dimensional nanomaterials are very promising sensors, and some of their results have shown that the devices based on onedimensional nanostructures have great potential in overcoming the fundamental limitations of traditional nanomaterials based on sintered particles or thick-films such as low sensitivity, poor stability and high working temperature.$^{68-71}$ Aligned zinc oxide nanorods synthesized via a two-step solution approach on an $\mathrm{Al}_{2} \mathrm{O}_{3}$ tube were exhibited responses of 18.29 and 10.41 to $100 \mathrm{ppm}$ ethanol and hydrogen, respectively, which occurs due to larger effective surface area of the aligned nanorods.$^{72}$

Tin oxide based nanomaterials have received a great attention in the fabrication of gas sensors devices. Pure tin oxide and their composites have been used for reducing gas sensors.$^{73-74}$ Pure $\mathrm{SnO}_{2}$ by sol-gel method and their mixture with $\mathrm{CuO}, \mathrm{Ag}_{2} \mathrm{O}, \mathrm{Al}_{2} \mathrm{O}_{3}$, and $\mathrm{La}_{2} \mathrm{O}_{3}$ by hydrothermal route with average particle size of $6 \mathrm{~nm}$ were prepared to study the characteristics of LPG gas. The $\mathrm{CuO} 2 \mathrm{wt} \%$ doped $\mathrm{SnO}_{2} 5 \mathrm{wt} \%$ exhibited better gas sensing properties with good response time (15s) and recovery time (30s) in comparison to pure as well as other doped composites of it.$^{73}$ The $\mathrm{SnO} 2 \mathrm{NWS}$ were grown at $980^{\circ} \mathrm{C}$ on $\mathrm{Si}$ substrates deposited with Au catalyst while hierarchical $\mathrm{SnO}_{2}$ nanostructures were produced at $800^{\circ} \mathrm{C}$ with $\mathrm{Sn}$ powder as the source. Hierarchical $\mathrm{SnO}_{2}$ nanostructures have enhanced sensing performance to $\mathrm{LPG}$ and $\mathrm{NH}_{3}$ gases in comparison with $\mathrm{SnO}_{2} \mathrm{NWs}$ ${ }^{74}$ This is due to high porosity, more active sites and addition of coreouter junctions to the materials.

Generally pure oxide nanomaterials based gas sensors need to be operated at relatively high temperatures rendering their practical application difficult. To overcome this problem among all the surfacereacting materials, carbon nanotubes (CNTs) having unique geometry and amazing structural features appear as a potential candidate for gas sensors ${ }^{75}$ For enhancing the response and lowering the working temperature of nanomaterials, many efforts have been made. Since Last few years, carbon nanotubes (CNTs) have been used due to its unique geometry and amazing structural features appear as a potential candidate for gas sensors . ${ }^{75-76}$ Nguyen Duc Hoa et al. ${ }^{75}$ reported simple method to fabricate an ammonia gas sensor with a nanocomposite of single-walled carbon nanotubes ( $\mathrm{SWNTs}$ ) and $\mathrm{SnO}_{2}$ with fast response time of $\sim 100 \mathrm{~s}$ and quick recovery behaviour. The composite sensor can detect the concentration of $\mathrm{NH}_{3}$ down to the $10 \mathrm{ppm}$ level at room temperature and atmospheric pressure.

Tungsten trioxide nanomaterials have also received great attention for gas sensing applications. Pure $\mathrm{WO}_{3}$ nanomaterials and their composites with modified morphology have been used for the detection of reducing gases. Xiang Q et al. ${ }^{78}$ reported a special method for uniformly attaching monodispersed Au NPs onto the surface of WO3 nanorods for $\mathrm{H}_{2}$ gas sensing. These sensors show highest response to $50 \mathrm{ppm} \mathrm{H}_{2}$ at $290^{\circ} \mathrm{C}$ in a mixture of several kinds of reducing gases $\left(\mathrm{H}_{2}, \mathrm{CO}, \mathrm{C}_{2} \mathrm{H}_{5} \mathrm{OH}, \mathrm{CH}_{3} \mathrm{OH}, \mathrm{HCHO}, \mathrm{NH}_{3}\right)$ with good response $(8 \mathrm{~s})$ and recovery time $(10 \mathrm{~s})$ to which confirms a high selectivity and response sensitivity of $\mathrm{H}_{2}$ on the Au NP@WO NR composite ${ }^{75}$ In addition stability is also a measure factor which must be considered and verified as being acceptable to be used for practical application. These exhibited high long term stability in their response and selectivity for detecting $\mathrm{H}_{2}$ gas.

WO3 thick films prepared by screen printing method were investigated at different operating temperatures and gas concentrations. These thick films exhibit excellent LPG sensing properties with maximum sensitivity $\square 133 \%$ at $400^{\circ} \mathrm{C}$ with fast response and recovery time and can be reliably used to monitor the concentration of LPG over the range (25-100 ppm).$^{76}$

$\mathrm{SnO}_{2}$ activated $\mathrm{Cr}_{2} \mathrm{O}_{3}$ thick film is also investigated to sense Ethanol and LPG gas. ${ }^{77}$ Instead of pure sensor the sensing response to ethanol is found to be two times for $\mathrm{SnO}_{2}$ activated $\mathrm{Cr}_{2} \mathrm{O}_{3}$ thick film sensors. The addition of tin chloride solution on the sensor surface brought maximum reduction in activation energy of base materials and hence enhancing the sensing response to ethanol. The ethanol gas sensing reaction occurs under two different ways i.e. either dehydration or dehydrogenation process due to acidic nature or basic nature of sensor material respectively. ${ }^{78,79}$ Organic materials, such as poly pyrrole (PPy), poly aniline (PANI), and metaphthalocyanines, have been used for enhancing the gas sensing characteristics for a long time.$^{80-83}$ These materials provide long response time due to the orderly structure hinders. Organic materials doped nanomaterials like Poly Aniline (PANI), Poly Aniline/Titanium dioxide ( $\mathrm{PANI} / \mathrm{TiO}_{2}$ ), Poly Aniline/ Tin Oxide $\left(\mathrm{PANI} / \mathrm{SnO}_{2}\right)$ and Poly Aniline/thin films developed by insitu self assembly method were also investigated for $\mathrm{NH}_{3}$ gas sensing application ${ }^{84} \mathrm{PANI} / \mathrm{TiO}_{2}$ nanocomposite thin film sensor showed optimum $\mathrm{NH}_{3}$ gas-sensing characteristics rather than pure organic material based thin film sensor and their other composites. PANI doped nanocomposite thin film sensors have shown faster response/ recovery rate, higher sensitivity, better reproducibility and long-term stability. Such characteristics reveal that PANI nanocomposite thin film sensors are highly potential candidates for NH3 detection, and perspective for electronic nose application.

Many reports are focused on nanomaterials hetero junctions i.e. two layer type nanomaterials development to sense different gases ${ }^{85-89}$ The amorphous/porous nature of the silicon deposited by the plasma enhanced chemical vapor deposition technique was used under bias condition to enhance the sensitivity towards ethanol and water vapors ${ }^{85} \mathrm{~A}$ higher temperature sensor was reported by Ling and Leach towards humidity and $\mathrm{NO}_{2}$ using a $\mathrm{SnO} / \mathrm{WO}_{3}$ hetero junction in pellet form ${ }^{86}$ Transparent oxides $\mathrm{p}$-n hetero junction diodes based on $\mathrm{SrCu}_{2} \mathrm{O}_{2}-\mathrm{ZnO}$ were fabricated with post-annealing treatment at $923 \mathrm{~K}$ and the effect of $\mathrm{H}_{2}$ and $\mathrm{CO}$ gas introduction on the currentvoltage characteristic was studied by Nakamura et al. ${ }^{87}$ Recently, a few reports have emerged for room temperature LPG sensors based on electrochemically deposited p-poly aniline with n-CdTe deposited by the electrochemical method ${ }^{88}$ Ladhe RD et al. ${ }^{89}$ was used room temperature soft chemical route for producing $n-\mathrm{Bi}_{2} \mathrm{~S}_{3}$ films followed by $\mathrm{p}-\mathrm{CuSCN}$ films onto Fluorine doped Tin Oxide (FTO) coated glass substrates for LPG gas sensor at room temperature. The device exhibited more than $70 \%$ response at $1370 \mathrm{ppm}$ of LPG because upper porous structure allowed enough room for the gas species to 
adsorb and de-adsorb easily at the interface ${ }^{89}$ The nanocomposites of $\mathrm{ZnO}$ with $\mathrm{CdO}$ synthesized by sol-gel pyrolysis method based on polymeric network of polyvinyl Alcohol (PVA) of nanograin's diameter varying from 70 to $90 \mathrm{~nm}$ were used for CO gas detection. Such nanocomposite exhibits good ability to detect $\mathrm{CO}$ gas.$^{90}$

One-dimensional (1D) nanostructures (nanowires, nanotubes, nanorods) have received considerable attention due to their unique properties and novel applications and can be developed including VLS (Vapor-Liquid-Solid), SLS (Solution-Liquid-Solid), templatebased synthetic approaches and laser ablation.$^{91-94}$ Dang Thi Thanh Le et al. ${ }^{95}$ reported preparation of $\mathrm{TiO}_{2}$ nanowires by a hydrothermal process in $\mathrm{KOH}$ solution for LPG gas sensing analysis. The obtained nanowires diameter of ca. 10-20 nm and length of ca. 700-800 nm exhibited good response to LPG concentrations of 500, 1000, 2000, 4000 and $8000 \mathrm{ppm}$ at operating temperature of $400^{\circ} \mathrm{C} .{ }^{95}$

Detection of volatile organic compounds is important since these are used in many fields like chemical industries, laboratories which are very harmful for living species. Many researchers have also focused on developing to sense these harmful organic compounds at low concentrations. Al-doped $\mathrm{ZnO}$ thin films prepared by chemical spray pyrolysis were used as methanol sensors. Al- doped $\mathrm{ZnO}$ thin films show high sensitivity to methanol vapor in compare to undoped $\mathrm{ZnO}$ film at $275 \mathrm{C}$ to $500 \mathrm{ppm}$ with fast response and recovery time.$^{96} \mathrm{~A}$ novel $\mathrm{ZnO}$ porous nanosolid with a very uniform pore size fabricated by hydrothermal hot-press method were also used for analysing sensing applications towards several organic vapors.$^{97}$

Wang $\mathrm{HC}$ et al. ${ }^{98}$ reported the method of fabrication of $\mathrm{SnO}_{2}$ thin film gas sensors towards methyl alcohol vapors operating at room temperature. The sensors exhibit ultra-fast and reversible electrical response ( $\mathrm{t} 90 \% \square 5 \mathrm{~s}$ for response and $\square 1 \mathrm{~s}$ for recovery) at room temperature. . The particle size of the hydrolyzed SnCl4 affects the sensitivity of the sensors, but does not have much effect on their response time. The responses of sensors prepared from the precursor solutions with the colloid particle size of $6.0,30.3,49.2$ and $319.9 \mathrm{~nm}$ were found to be $241,318,363$ and 326 , respectively. These sensors show fast electrical response and were highly reversible for both the sensing and the recovery process irrespective of the particle size.$^{98}$ Thorsten Wagner et al. ${ }^{99}$ synthesized the ordered mesoporous $\mathrm{SnO} 2$ powders with large specific surface area by using Cetyl Trimethyl Ammonium Bromide (CTABr) as a structure-directing and used for the preparation of gas sensors by application to commercial sensor supports. Such a materials show a fast and intense response to low concentrations of $\mathrm{CO}$ as well as a remarkably strong insensitivity against humidity.

Babita Baruwati et al. ${ }^{100}$ reported Highly crystalline zinc oxide $(\mathrm{ZnO})$ nanoparticles prepared via hydrothermal route at $120^{\circ} \mathrm{C}$ over a range of different time period ${ }^{100}$ were used for sensing of reducing gases like Liquefied Petroleum Gas (LPG), Ammonia, Hydrogen, Ethanol (EOH), etc. These nanoparticles show high sensitivity to LPG and Ethanol at relatively low operating temperatures. Palladium is known to have a catalytic effect due to its excellent oxidation capability to convert hydrocarbons at lower temperatures.$^{101}$ making the sensor selective to hydrocarbons. In $\mathrm{Pb}-\mathrm{ZnO}$ nanoparticles barrier is formed at the interface that is fully characterized by the electron affinity. $\mathrm{Pd}$ incorporation with $\mathrm{ZnO}$ results in a decrease in operating temperature by more than $100^{\circ} \mathrm{C}$, and improves the sensing characteristics in terms of response and recovery times.

Undoped and Sb-doped needle-shaped ZnO nanoparticles produced by vapor condensation method were investigated for Volatile Organic Compounds (VOCs), benzene, toluene, xylene, acetone and alcohol, as a function of temperature. The doping of $\mathrm{Sb}$ to $\mathrm{ZnO}$ nanoparticles modified the morphology of the doped materials from needle shape to polygon which is found to be greatly useful in improving the gas sensitivity ${ }^{102}$

$\mathrm{ZnO}$ thin films prepared by sol-gel dip coating method were also used for investigating gas-sensing properties of the multi-layers for alcohols with different chain lengths (Methanol, Ethanol and Propyl Alcohol vapor).$^{103}$ The film of these nanomaterials was sensible to Methanol, Ethanol and Propyl Alcohol vapor as low concentration as 1,10 and $0.5 \mathrm{ppm}$, respectively. This film shows with good sensitivity to the test gases with quick response-recovery characteristics, i.e., the sensitivity of the film to $10 \mathrm{ppm}$ gases is 2.1, 5.1 and 18.1 to Ethanol, Methanol, and Propyl Alcohol vapor.

Komilla Suri et al. ${ }^{104}$ reported that magnetic nanomaterials and their nanocomposites were also play a great role in gas sensing applications.$^{28}$ Nanocomposites of iron oxide and poly pyrrole fabricated by simultaneous gelation and polymerisation process were analysed for humidity gas sensing application. These nanocomposites were showing the increment in response with increasing poly pyrrole concentration. These sensors were also investigating for $\mathrm{CO}_{2}, \mathrm{~N}_{2}$, and $\mathrm{CH}_{4}$ with varying pressure. According to the above these were highly sensitive according to the following order $\mathrm{CO}_{2 \mathrm{~N} 2 \mathrm{CH} 4}$. This happened due to variation in kinetic diameter of the gas molecules having the order $\mathrm{CO}_{2}<\mathrm{N}_{2}<\mathrm{CH}_{4} \cdot{ }^{104}$

Weber IT et al. ${ }^{105}$ reported a pechini method for preparing $\mathrm{SnO}_{2}$. $\mathrm{Nb}_{2} \mathrm{O}_{5}$ powder in nano range for an Ethanol vapor sensor. The use of $\mathrm{Nb}_{2} \mathrm{O}_{5}$ inhibits the particle growth and also to increase the conductivity of $\mathrm{SnO}_{2}$ and hence improved the sensing performance. ${ }^{105} \mathrm{Ji}$ Haeng $\mathrm{Yu}$ et al. ${ }^{106}$ reported the $\mathrm{ZnO}-\mathrm{SnO}_{2}$ composites for $\mathrm{CO}$ gas sensing. ${ }^{106}$ $\mathrm{He}$ explained that $\mathrm{SnO}_{2}$-rich samples as well as $\mathrm{ZnO}$ rich samples are more sensitive to $\mathrm{CO}$ gas than pure materials. This is happened due to more porous microstructures. $\mathrm{He}$ also reported that $\mathrm{CuO}$ and $\mathrm{ZnO}$ doped $\mathrm{SnO}_{2}$ nanocomposites for $\mathrm{CO}$ gas detection. $\mathrm{CuO}$ and $\mathrm{ZnO}$ doped $\mathrm{SnO}_{2}$ gas sensor were prepared by ball milling method to detect $\mathrm{CO}$ and $\mathrm{H}_{2}$ gases.$^{107}$ The $\mathrm{CuO}$ added $\mathrm{SnO}_{2}$ sensor show good sensitivity to $200 \mathrm{ppm} \mathrm{CO}$ with varying concentration of $\mathrm{CuO}$. Pure $\mathrm{SnO}_{2}$ exhibits maximum sensitivity at $350^{\circ} \mathrm{C}$ while addition of $\mathrm{CuO}$ to it reduces the operating temperature $150-200^{\circ} \mathrm{C}$. The addition of $\mathrm{ZnO}$ into the $\mathrm{CuO}$ doped $\mathrm{SnO}_{2}$ slightly shifted the $\mathrm{H}_{2}$ gas sensing curve to a higher temperature while detect the $\mathrm{CO}$ relatively at low temperature. $\mathrm{ZnO}$ and $\mathrm{Sb}$ doped $\mathrm{ZnO}$ nanoparticles produced by sol-gel method investigated for $\mathrm{O}_{2}$ and $\mathrm{CO}_{2}$ gas sensing were reported by Kashyout $\mathrm{AB}$, et al. ${ }^{108}$ The gas sensitivity was higher for $\mathrm{O}_{2}$ gas than $\mathrm{CO}_{2}$, and the sensitivity improved to $\mathrm{Sb}$ doping with maximum enhancement at $\mathrm{Zn}: \mathrm{Sb}(93: 7){ }^{108}$ Hence there are various types of nanomaterials which play a role in gas sensing.

\section{Conclusion}

In this review, we discuss the synthesis of nanomaterials, importance of nanomaterials in gas sensor devices, working principle and their sensing mechanism. Several kinds of nanomaterials have been used to detect a range of toxic, hazardous gases. Both nanomaterials and their nanocomposites are responding to both types of gases (reducing and oxidising gases). Composite nanomaterials show better sensitivity to the target gas than the pure nanomaterials at optimum working temperature. Many efforts have been done to enhance the sensitivity like by using good catalyst, surface capping/ structure directing agents, modifying morphology etc. Porous nanostructures with high surface to volume ratio of nanomaterials seem to be useful for gas sensing. These nanostructures have lots of active sites with pores among them. 
Since the gas sensitivity also depends upon the nano particle size. It is also showed that the sensitivity is enhanced by reducing the grain size. Working temperature is also a major issue in gas sensing analysis. Pure nanomaterials are sensible to target gases at high temperature (150$\left.450^{\circ} \mathrm{C}\right)$. So, it is necessary to reduce the working temperature and enhance the sensitivity of nanomaterials. Usually carbon nanotubes/ graphenes are used to keep a balance in between lowering the working temperature and enhancing the sensitivity. Besides these, Humidity also affects the gas sensitivity of nanomaterials which is removed by heating the sensor device at optimum temperature.

\section{References}

1. Krätschmer W, Lowell DL, Fostiropoulos K, Donald RH Solid C60: a new form of carbon. Nature. 1990;347:354-358.

2. Sumio Iijima Helical microtubules of graphitic carbon. Nature. 1991;354:56-58.

3. Ebbesen TW, Ajayan PM Large scale synthesis of carbon nanotubes. Nature. 1992;358:220-222.

4. Kresge CT, Leonowicz ME, Roth WJ, Vartuli JC, Beck JS Ordered mesoporous molecular sieves synthesized by a liquid crystal template mechanism. Nature. 1992;359:710-712.

5. Benxia Li, Yanfen Wang Facile Synthesis and Enhanced Photocatalytic Performance of Flower-like ZnO Hierarchical Microstructures. J Phys Chem C. 2010;114(2):890-896.

6. Jong Heun Lee Gas sensors using hierarchical and hollow oxide nanostructures: Overview. Sensors and Actuators B: Chemical. 2009;140(1):319-336.

7. Özgür Ü, Alivov YaI, Liu C, Teke A et al. A comprehensive review of ZnO materials and device. J Appl Phys. 2005;98:041301.

8. Dutta $\mathrm{S}$, Ganguly $\mathrm{BN}$ Characterization of $\mathrm{ZnO}$ nanoparticles grown in presence of Folic acid template. J Nanobiotechnology. 2012;10:29.

9. Ana Maria G, Diana B, Lucian R et al. Manganese oxide based screenprinted sensor for xenoestrogens detection. Sensors and Actuators B: Chemical. 2015;210:273-280.

10. Nanto $\mathrm{H}$, Morita $\mathrm{T}$, Habara $\mathrm{H}$ et al. Doping effect of $\mathrm{SnO} 2$ on gas sensing characteristics of sputtered $\mathrm{ZnO}$ thin film chemical sensor. Sensors and Actuators B: Chemical. 1996;36(1-3):384-387.

11. Tripti Shukla Synthesis of Tin Oxide thick film and its investigation as a LPG Sensor at Room temperature. JST. 2012;2(3):102-108.

12. Raluca S, Miguel AP, Ednan J et al. Grain size effect on the electrical response of SnO2 thin and thick film sensors. Mat. 2009;12(1):83-87.

13. Vaezi MR, Sadrnezhaad S Gas sensing behaviour of nanostructured sensors based on tin oxide synthesized with different methods. Materials Science and Engineering: B. 2007;140(1-2):73-80.

14. Jia GL, Paichun C, Zhiyong F Quasi-one dimensional metal oxides materials synthesis, properties and applications. Materials Science and Engineering: R: Reports. 2006;52(1-3): 49-91.

15. Andrei $\mathrm{K}$, Martin $\mathrm{M}$ Chemical sensing and catalysis by one dimensional metal oxide nanostructures. Annurev matsci Research. 2004;34:150-180.

16. In Sung H, Sun Jung K, Joong Ki C et al. Synthesis and gas sensing characteristics of highly crystalline $\mathrm{ZnO}-\mathrm{SnO} 2$ core-shell nanowires. Sensors and Actuators B: Chemical. 2010;148(2):595-600.

17. Song X, Wang Z, Liu Y, Wang C, Li L A highly sensitive ethanol sensor based on mesoporous $\mathrm{ZnO}-\mathrm{SnO} 2$ nanofibres. Nanotechnology. 2009;20(7):075501.

18. Jia Q, Ji H, Zhang $\mathrm{Y}$ et al. Rapid and selective detection of acetone using hierarchical $\mathrm{ZnO}$ gas sensors for hazardous odor markers application. $J$ Hazard Mater. 2014;276:262-270.
19. Liwei W, Yanfei K, Yao Wang et al. CuO nanoparticle decorated $\mathrm{ZnO}$ nanorods sensor for low temperature $\mathrm{H}_{2} \mathrm{~S}$ detection. Materials Science \& Engineering C. 2012;32(7):2079-2085.

20. Sennik E, Necmettin K, Zafer Ziya O Electrical and VOC sensing properties of anatase and rutile $\mathrm{TiO} 2$ nanotubes. Journal of Alloys and Compounds. 2014;616:89-96.

21. Sang KL, Sung HH, Daeic Chang, Soonhyun K Preparation of mesoporous In2O3 nanofibres by electro spinning and their application as a $\mathrm{CO}$ gas sensor. Sensors and Actuators B: Chemical. 2010;149(1):28-33.

22. Baoyou G, Fangming Z, Caihong F et al. A facile coordination compound precursor route to controlled synthesis of $\mathrm{Co} 3 \mathrm{O} 4$ nanostructures and their room temperature gas sensing properties. $J$ Mater Chem. 2008;18:4977-4984

23. Gao T, Wang TH Synthesis and properties of multipod-shaped $\mathrm{ZnO}$ nanorods for gas-sensor applications. Applied Physics A. 2005;80(7):1451-1454.

24. Baratto C, Sberveglieri G, Onischuk A et al. Low temperature selective $\mathrm{NO} 2$ sensors by nanostructured fibres of $\mathrm{ZnO}$. Sensors and Actuators $\mathrm{B}$ : Chemical 2004;100(1-2):261-265.

25. Shiva S, Pratima C LPG Gas Sensing Applications of $\mathrm{SnO} / \mathrm{ZnO}$ Nanoparticles. Advanced Science Letters. 2014;20(5-6):1198-1203.

26. Toshihiro Arai (The study of the optical properties of conducting tin oxide films and their interpretation in terms of a tentative band scheme. J Phys Soc Jpn. 1960;15(5): 916-927.

27. Xianghong L, Zhang J, Wang L, Taili Y, Xianzhi G 3D hierarchically porous $\mathrm{ZnO}$ structures and their functionalization by Au nanoparticles for gas sensors. J Mater Chem. 2011;21(2):349-356.

28. Komilla Suri, Annapoorni S, Sarkar AK et al. Gas and humidity sensors based on iron oxide polypyrrole nanocomposites. Sensors and Actuators B: Chemical. 2002;81(2-3):277-282.

29. Zhang YX, Li GH, Jin YX, et al. Hydrothermal synthesis and photoluminescence of $\mathrm{TiO} 2$ nanowires. Chemical Physics Letters. 2002;365(3-4):300-304.

30. Keshmiri SH, Rokn Abadi MR. Enhancement of drift mobility of zinc oxide transparent-conducting films by a hydrogenation process. Thin Solid Films. 2001;382(1-2):230-234.

31. Shinde VR, Gujar TP, Lokhande CD, et al. Use of chemically synthesized $\mathrm{ZnO}$ thin film as a liquefied petroleum gas sensor. Materials Science and Engineering: B. 2007;137(1-3):119-125.

32. Ke Yu, Yongsheng $\mathrm{Z}$, Rongli $\mathrm{Xu}$, et al. Field emission behavior of cuboid zinc oxide nanorods on zinc-filled porous silicon. Solid State Communications. 2005;133(1):43-47.

33. Dongzhi Z, Yane S, Yong Z. Fabrication and characterisation of layer by layer nano self assembled $\mathrm{ZnO}$ nanorods/ carbon nanotube film sensor for ethanol gas sensing application at room temperature. Journal of Materials Science: Materials in Electronics. 2015;26(10):7445-7451.

34. Fang F, Bai L, Song D, et al. Ag-modified In2O3/ZnO nanotubes with High formaldehyde gas sensing performance. Sensors (Basel). 2015;15(8):20086-20096.

35. Jianxiong W, Sun XW, Ying Yang, et al. Hydrothermal grown oriented $\mathrm{ZnO}$ nanorods arrays for gas sensing applications. Nanotechnology. 2006;17(19):4995-4998.

36. Gou X, Li R, Wang G, et al. Room temperature solution synthesis of $\mathrm{Bi} 2 \mathrm{O} 3$ nanowires for gas sensing application. Nanotechnology. 2009;20(49):495501.

37. Guoxiu W, Xinglong G, Josip H, et al. Facile Synthesis and Characterization of Iron Oxide Semiconductor Nanowires for Gas Sensing Application. J Phys Chem C. 2008;112(39):15220-15225. 
38. Choi, Hwang YJ, Park IS, et al. Novel fabrication of an $\mathrm{SnO} 2$ nanowire gas sensor with high sensitivity. Nanotechnology. 2008;19(9):095508.

39. Seal S, Shukla S. Naocrystalline SnO gas sensors in view of surface reactions and modifications. JOM. 2002;54(9):35-38.

40. Ménil F, Véronique C, Claude L. Critical review of nitrogen monoxide sensors for exhaust gases of lean burn engines. Sensors and Actuators B: Chemical. 2000;67(1-2):1-23.

41. Misook Kang. Methanol conversion on metal incorporated SAPO-34s (MeAPSO-34s). Journal of Molecular Catalysis A: Chemical. 2000;160(2):437-444.

42. Moens L, Ruiz P, Delmon B, et al. Evaluation of the role played by bismuth molybdates in Bi2Sn2O7-MoO3 catalysts used for partial oxidation of isobutene to methacrolein. Applied Catalysis A: General. 1999;180(1-2):299-315.

43. Kunga MC, Kunga HH. IR studies of NH3, Pyridine, CO and NO adsorbed on transition metaloxides. Catalysis Reviews: Science and Engineering. 1985;27(3):425-460.

44. Linsebigler AM, Guangquan L, Yates JT. Jr. Photocatalysis on TiO2 surfaces: principles, mechanisms and selected results. Chem Rev. 1995;95(3):735-758.

45. Segal SR, Suib SL. Photo assisted decomposition of dimethyl methy phosphonate over amorphous manganese oxide catalysts. Chem Mater. 1999;11(7):1687-1695.

46. Kohl D. Surface processes in the detection of reducing gases with SnO2-based devices. Sensors and Actuators. 1989;18(1):71-113.

47. Tschulena G, Andreas Lahrmann. Sensors in Household Applications in Sensors Application. Hardcover. 2003;5:1-310.

48. Yamazoe N, Kurokawa Y, Seiyama T. Effects of additives on semiconductors gas sensors. Sensors and Actuators. 1983;4:283-289.

49. Trivikrama Rao GS, Tarakarama Rao D. Gas sensitivity of ZnO based thick film sensor to NH3 at room temperature. Sensors and Actuators B: Chemical. 1999;55(2-3):166-169.

50. Ming Kang Y, Zu Wan B. Gold and iron supported on Y-type Zeolite for carbon monoxide oxidation. Catalysis Today. 1997;35(4):379-392.

51. Mohamed AA, Mubarak AT, Marestani ZM, et al. Highly sensitive and selective catalytic determination of formaldehyde and acetaldehyde. Talanta. 2008;74(4):578-585.

52. Mitchell MB, Sheinker VN, Tesfamichael AB, et al. Decomposition of dimethyl methylphosphonate (DMMP) on supported cerium and iron co impregnated oxides at room temperature. $J$ Phys Chem B. 2003;107(2):580-586.

53. Yamazoe N. Toward innovations of gas sensor technology. Sensors and Actuators B: Chemical. 2005;108(1-2):2-14.

54. Gupta SK, Aditee Joshi, Manmeet Kaur. Development of gas sensors using $\mathrm{ZnO}$ nanostructures. Journal of Chemical Sciences. 2010;122(1):57-62.

55. Bai Shouli, Liangyuan C, Li D, et al. Different morphologies of $\mathrm{ZnO}$ nanorods and their sensing property. Sensors and Actuators B: Chemical. 2010;146(1):129-137.

56. Bagheri M, Khodadadi AA, Mahjoub AR, et al. Highly sensitive Gallia$\mathrm{SnO} 2$ nanocomposite sensors to $\mathrm{CO}$ and ethanol in presence of methane. Sensors and Actuators B: Chemical. 2013;188:45-52.

57. Min Liao Z, Zhou ZH, Zhou YB, et al. Surface effects on photoluminescence of single $\mathrm{ZnO}$ nanowires. Physics Letters A. 2008;372(24):4505-4509.

58. Bai Shouli, Chen L, Li Dianqing, et al. Different morphologies of $\mathrm{ZnO}$ nanorods and their sensing property. Sensors and Actuators B: Chemical. 2010;146(1):129-137.
59. Prabhakar R, Tae Yu Y. Citrate-assisted hydrothermal synthesis of single crystalline $\mathrm{ZnO}$ nanoparticles for gas sensor application. Sensors and Actuators B: Chemical. 2012;173:58-65.

60. Oleg Lupan, Guangyu C, Lee Chow. Novel hydrogen gas sensor based on single $\mathrm{ZnO}$ nanorods. Microelectronic Engineering. 2008;85:2220-2225.

61. Romppainen P, Lantto V. The effect of microstructure on the height of potential energy barriers in porous tin dioxide gas sensors. J Appl Phys. 1998;63(10):5159-5165.

62. Yang JI, Lim H, Do Han S. Influence of binder on the sensing and electrical characteristics of WO3 based gas sensors. Sensors and Actuators B: Chemical. 1999;60(1):71-77.

63. Wang YD, Hui WX, Qun Su, et al. Ammonia sensing characteristics of $\mathrm{Pt}$ and $\mathrm{SiO} 2$ doped $\mathrm{SnO} 2$ materials. Solid State Electronics. 2001;45(2):347-350.

64. Joong KH, Heun LJ. Highly sensitive and selective gas sensors using p-type oxide semiconductors: overview. Sensors and Actuators B: Chemical. 2014;192:607-627.

65. Sivapunniyam A, Wiromrat N, Myint MTZ, et al. High performance liquefied petroleum gas sensing based on nanostructures of zinc oxide and zinc stannate. Sensors and Actuators B: Chemical. 2011;157(1):232-239.

66. Xiang Q, Guifang M, Yuan Z, et al. Ag nanoparticle embedded-ZnO nanorods synthesized via a photochemical method and its gas-sensing properties. Sensors and Actuators B: Chemical. 2010;143(2):635-640.

67. Yuan Zhang, Qun Xiang, Jiaqiang Xu, et al. Self-assemblies of $\mathrm{Pd}$ nanoparticles on the surfaces of single crystal $\mathrm{ZnO}$ nanowires for chemical sensors with enhanced performances. J Mater Chem. 2009; 19:4701-4706.

68. Matt Law, Hannes K, Messer B, et al. Photochemical sensing of NO2 with $\mathrm{SnO} 2$ nanoribbon nanosensors at room temperature. Angew Chem Int Ed. 2002;41(13):2405-2408.

69. Chao Li, Daihua Z, Xiaolei L, et al. In2O3 nanowires as chemical sensors. Appl Phys Lett. 2003;82(10):1613-1615.

70. Kolmakov A, Zhang Y, Cheng G, et al. Detection of CO and $\mathrm{O} 2$ using tin oxide nanowire sensors. Advanced Materials. 2003;15(12):997-1000.

71. Xu Jiaqiang, Chen Y, Yadong L, et al. Gas sensing properties of $\mathrm{ZnO}$ nanorods prepared by hydrothermal method. Journal of Materials Science. 2005;40(11):2919-2921.

72. jian BL, Na YX, Jing Y, et al. Nanopillar ZnO gas sensor for hydrogen and ethanol. Sensors and Actuators B: Chemical. 2007;126(2):604-608.

73. Hien VX, Anh Ly TH, Trung KQ, et al. LPG sensing properties of $\mathrm{SnO} 2$ nanoparticles doped with several metal oxides by a hydrothermal method. Adv Nat Sci Nanosci Nanotechnol. 2010;1(2):1025014.

74. Thong LV, Ngoc LLT, Van HN. Comparative study of gas sensor performance of $\mathrm{SnO} 2$ nanowires and their hierarchical nanostructures. Sensors and Actuators B: Chemical. 2010;150(1):112-119.

75. Duc Hoa N, Van Quy N, You Suk Cho, et al. Nanocomposite of SWNTs and $\mathrm{SnO} 2$ fabricated by soldering process for ammonia gas sensor application. physica status solidi (a). 2007;204(6):1820-1824.

76. Andzelm J, Govind N, Amitesh M. Nanotube based gas sensors-Role of structural defects. Chemical Physics Letters. 2006;421(1-3):58-62.

77. Valentini L, Armentano I, Kenny JM, et al. Sensors for sub-ppm NO2 gas detection based on carbon nanotube thin films. Appl Phys Lett. 2003;82(6):961.

78. Xiang QGF, Zhao HB, Zhang Y, et al. Au nanoparticle modified WO3nanorods with their enhanced properties for photo catalysis and gas sensing. J Phys Chem C. 2010;114(5):2049-2055. 
79. Khadayateb RS, Salia JV, Ranec SB, et al. Preparation and Characterization of WO3-Based Liquid Petroleum Gas Sensor Materials and Manufacturing Processes. 2007;22(2):277-280.

80. Ravi Chand S, Nipin Kohli, Singh MP, et al. Ethanol and LPG sensing characteristics of $\mathrm{SnO} 2$ activated $\mathrm{Cr} 2 \mathrm{O} 3$ thick film sensor. Bulletin of Materials Science. 2010;33(5):575-579.

81. Jiaqiang $\mathrm{Xu}$, Jianjun $\mathrm{H}$, Yuan Zhang, et al. Studies on alcohol sensing mechanism of $\mathrm{ZnO}$ based gas sensors. Sensors and Actuators B: Chemical. 2008;132(1):334-339.

82. Sadek AZ, Wlodarski W, Shin $\mathrm{K}$, et al. A layered surface acoustic wave gas sensor based on a polyaniline/In2O3 nanofibre composite, Nanotechnology. 2006;17(17):4488-4492.

83. Joshi SS, Lokhande CD, Sung HH. A room temperature liquefied petroleum gas sensor based on all-electrodeposited $n-C d S e / p-$ poly aniline junction. Sensors and Actuators B: Chemical. 2007;123(1):240-245

84. Huiling T, Yadong J, Xie G, et al. Preparation, Characterization and Comparative NH3-sensing Characteristic Studies of PANI/inorganic Oxides Nanocomposite Thin Films. Journal of Materials Science \& Technology. 2010;26(7):605-613.

85. Tucci M, Ferrara VL, Della NM, et al. Bias enhanced sensitivity in amorphous/porous silicon hetero junction gas sensors. Journal of NonCrystalline Solids. 2004;338-340:776-779.

86. Ling $\mathrm{Z}$, Leach $\mathrm{C}$. The effect of relative humidity on the $\mathrm{NO} 2$ sensitivity of a $\mathrm{SnO} 2 / \mathrm{WO} 3$ hetero junction gas sensor. Sensors and Actuators B: Chemical. 2004;102(1):102-106.

87. Nakamura Y, Yoshida Y, Honaga Y, et al. Design of a gas sensitive transparent hetero junction-The system $\mathrm{SrCu} 2 \mathrm{O} 2-\mathrm{ZnO}$. Journal of the European Ceramic Society. 2005;25(12):2167-2170.

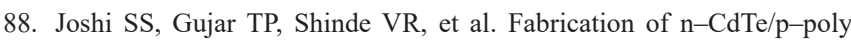
aniline hetero junction-based room temperature LPG sensor, Sensors and Actuators B: Chemical. 2008;132(1):349-355

89. Ladhe RD, Baviskar PK, Tan WW, et al. LPG sensor based on complete inorganic n-Bi2S3-p-CuSCN hetero junctions synthesized by a simple chemical route. Journal of Physics D: Applied Physics. 2010;43(24):245302.

90. Hassan Karami. Investigation of sol-gel Synthesized CdO-ZnO Nanocomposite for $\mathrm{CO}$ Gas Sensing. Int $J$ Electrochem Sci. 2010;5:720-730.

91. Zhang YX, Li GH, Jin YX, et al. Hydrothermal synthesis and photoluminescence of $\mathrm{TiO} 2$ nanowires. Chemical Physics Letters. 2002;365(3-4):300-304.

92. Trentler TJ, Hickman KM, Goel SC, et al. Solution-Liquid-Solid Growth of Crystalline III-V Semiconductors: An Analogy to VaporLiquid-Solid Growth. Science. 1995;270(5243):1791-1794.

93. Martin CR. Nanomaterials: A Membrane-Based Synthetic Approach. Science. 1994;26(5193):1961-1966.
94. Morales AM, Lieber CM. A Laser Ablation Method for the Synthesis of Crystalline Semiconductor Nanowires. Scinece. 1998;279(5348):208-211.

95. Thanh LDT, Vuong DD, Chien ND. Synthesis and LPG-sensing properties of TiO2 nanowires. J Phys Conf Ser. 2009;187(1):012086.

96. Sahaya PP, Nath RK. Al-doped $\mathrm{ZnO}$ thin films as methanol sensors. Sensors and Actuators B: Chemical. 2008;134(2):654-659.

97. Hongyan $\mathrm{Xu}$, Xiulin Liu, Deliang Cui, et al. A novel method for improving the performance of $\mathrm{ZnO}$ gas sensors. Sensors and Actuators B: Chemical. 2006;114(1):301-307.

98. Wang HC, Li Y, Yang MJ. Fast response thin film $\mathrm{SnO} 2$ gas sensors operating at room temperature. Sensors and Actuators B: Chemical. 2006;119(2):380-383.

99. Wagner T, Kohl CD, Fröba M, et al. Gas Sensing Properties of Ordered Mesoporous SnO2. Sensors. 2006;6(4):318-323

100. Babita B, Kishore Kumar D, Manorama SV. Hydrothermal synthesis of highly crystalline $\mathrm{ZnO}$ nanoparticles: A competitive sensor for LPG and EtOH. Sensors and Actuators B: Chemical. 2006;119(2):676-682.

101. Fernández García M, Martínez AA, Iglesias JA, et al. New strategies for the improvement of automobile catalysts. Int $\mathrm{J} \mathrm{Mol} \mathrm{Sci}$. 2001;2(5):251-262.

102. Zhua BL, Xieb CS, Zengb DW, et al. Investigation of gas sensitivity of $\mathrm{Sb}$-doped $\mathrm{ZnO}$ nanoparticles. Materials Chemistry and Physics. 2005;89(1):148-153.

103. Cheng XL, Zhao H, Huo $\mathrm{LH}$, et al. $\mathrm{ZnO}$ nanoparticulate thin film: preparation, characterization and gas-sensing property. Sensors and Actuators B: Chemical. 2004;102(2):248-252.

104. Komilla S, Annapoornib S, Sarkara AK, et al. Gas and humidity sensors based on iron oxide-poly pyrrole nanocomposites. Sensors and Actuators B: Chemical. 2002;81(2-3):277-282.

105. Weber IT, Andrade R, Leite ER, et al. A study of the $\mathrm{SnO} 2 . \mathrm{Nb} 2 \mathrm{O} 5$ system for ethanol vapour sensor: a correlation between microstructure and sensor performance. Sensors and Actuators B: Chemical. 2001;72(2):180-183.

106. Haeng YJ, Gyeong MC. Electrical and $\mathrm{CO}$ gas sensing properties of $\mathrm{ZnO}-\mathrm{SnO} 2$ composites. Sensors and Actuators B: Chemical. 1998;52(3):251-256.

107. Haeng $\mathrm{YJ}$, Gyeong $\mathrm{MC}$ Selective $\mathrm{CO}$ gas detection of $\mathrm{CuO}$ and $\mathrm{ZnO}$ doped $\mathrm{SnO} 2$ gas sensor. Sensors and Actuators B: Chemical. 2001;75(1-2):56-61.

108. Kashyout AB, Soliman HMA, Shokry Hassan H, Abousehly AM Fabrication of $\mathrm{ZnO}$ and $\mathrm{ZnO}$ : Sb Nanoparticles for Gas Sensor Applications. Journal of Nanomaterials. 2010 